\title{
Preparation of copper and silicon/copper powders by a gas evaporation-condensation method
}

\author{
J TEMUUJIN TE,,$*$ S P BARDAKHANOV $^{\mathrm{c}}$, A V NOMOEV ${ }^{\mathrm{d}}$, V I ZAIKOVSKII \\ A MINJIGMAA ${ }^{\mathrm{b}}$, G DUGERSUREN ${ }^{\mathrm{b}}$ and A VAN RIESSEN ${ }^{\mathrm{a}}$ \\ ${ }^{a}$ Centre for Materials Research, Department of Imaging and Applied Physics, Curtin University of Technology, \\ GPO Box U1987, Perth WA 6845 Australia \\ ${ }^{\mathrm{b}}$ Institute of Chemistry and Chemical Technology, Mongolian Academy of Sciences, Ulaanbaatar 51, Mongolia \\ ${ }^{c}$ Khristianovich Institute of Theoretical and Applied Mechanics, Institutskaya str., 4/1, 630090 Novosibirsk, Russia \\ ${ }^{\mathrm{d}}$ Buryat State University, Smolina str., 24, Ulan-Ude 670000, Russia \\ ${ }^{\mathrm{e} B o r e s k o v ~ I n s t i t u t e ~ o f ~ C a t a l y s i s ~ S B ~ R A S, ~ N o v o s i b i r s k ~ 630090, ~ R u s s i a ~}$
}

MS received 16 September 2008; revised 20 January 2009

\begin{abstract}
Pure and silicon-coated metal copper nano to submicron-sized powders were prepared by gas evaporation and condensation. This powder was synthesized by using an industrial electron accelerator, ELV6, with Ar as the carrier gas. Vapour from the liquefied metal surface was transferred to the cold zone by the carrier gas and precipitated as spherical $\mathrm{Cu}$ metal and $\mathrm{Si} / \mathrm{Cu}$ composite powders. The mean diameter of the resulting powder was $100-200 \mathrm{~nm}$.
\end{abstract}

Keywords. Copper powder; $\mathrm{Si} / \mathrm{Cu}$ composite particle; gas evaporation-condensation method; characterization.

\section{Introduction}

Preparation of metal powders is important for the development of modern science and engineering. The properties of powders can be selectively controlled by varying the size, morphology, and composition of the particles, producing new substances with enhanced or entirely different properties from their parent bulk materials (Gleiter 2000). One of the important metal powders is $\mathrm{Cu}$, which shows high electrical conductivity and plays an important role in electronics, catalysts, resins, and thermally conducting materials (Liu et al 2007).

There are several methods for preparing nano to micron sized copper powder, including a mild hydrothermal process (Liu et al 2007), a pulsed power technique (Sarathi et al 2006), mechanical milling (Wu et al 1998; Srikanth et al 2004) and wet chemical methods (Hsu et al 1990; Kim et al 2007). Previous authors were able to obtain up to $20 \mathrm{~g}$ solid particles (Hsu et al 1990) and should be considered as low yield. Also, when particle sizes are reduced to nano range they tend to self ignite (Ilyin 2007) which must be avoided. One commonly used way of reducing the self ignition is passivating the nanopowders with a thin oxide layer by slow oxidation of the metal powders. Another method for avoiding self

\footnotetext{
*Author for correspondence (jtemuujin@yahoo.com)
}

ignition of copper is by directly encapsulating the copper with a thin layer of another compound. For this work silicon has been chosen as the coating compound. For the preparation of pure copper and copper-based composite particles we have used the solid substance evaporation and condensation method originally proposed by Ramsey and Avery (1974), whose work was limited by the low power of their equipment and the low pressure of their carrier gas.

We have previously successfully prepared other nanosized oxides $\left(\mathrm{SiO}_{2}, \mathrm{MgO}, \mathrm{Al}_{2} \mathrm{O}_{3}, \mathrm{Y}_{2} \mathrm{O}_{3}, \mathrm{Gd}_{2} \mathrm{O}_{3}, \mathrm{TiO}_{2}\right.$ ) and metal powders (Ta, Al, Mo, Ni, Ag, Si) by using a powerful industrial electron beam accelerator (Bardakhanov et al 2006; Terekhov et al 2008). This method showed very promising results and allowed a large amount of nano to micron sized powders to be prepared.

The objectives of the present work were to produce pure copper and silicon-coated copper fine powder using the evaporation and condensation technique and to characterize the products.

\section{Experimental}

An industrial ELV-6 electron accelerator was used for the synthesis of copper and copper/silicon composites. This device and its principle of operation have been described elsewhere (Korchagin et al 2005; Bardakhanov et al 2006). ELV-6 electron accelerator included a system of 
differential pumping allowing the concentrated electron beam to be discharged from the vacuum into the atmosphere. The electron energy is $1.4 \mathrm{MeV}$, with beam powers ranging from 0 to $100 \mathrm{~kW}$ (beam current up to $75 \mathrm{~mA}$ ) and a beam power density of $5 \times 10^{6} \mathrm{~W} / \mathrm{cm}^{2}$ at the outlet to the atmosphere. Initially a copper ingot was melted in a graphite crucible at low power density and the power was then increased to evaporate the liquid copper. Ar was used at atmospheric pressure as the carrier gas to transfer the vaporized copper to the cold zone where it condensed. However, construction of the equipment does not allow to measure temperature continuously during the gas transfer and condensation. The resulting powder was collected in a woven filter. Copper/silicon composite powders were prepared in the same manner, by initially melting silicon metal (with proportion relative to $\mathrm{Cu}$, about $1: 20$ ) in the graphite crucible, then adding copper and melting to obtain a homogeneous liquid of copper and silicon. The beam power was then increased to evaporate the copper and silicon from the liquid. The rapid heating rate (as high as $1000^{\circ} \mathrm{C} / \mathrm{s}$ ) ensured the simultaneous evaporation of copper and silicon. The condensed nano powders were again collected in a woven filter.

$\mathrm{X}$-ray analysis (XRD) of the powders was performed using an HZC-4C diffractometer with Co radiation $(40 \mathrm{kV}$, $30 \mathrm{~mA}$, step size 0.05 degree). Transmission electron microscopy (TEM) was carried out with a JEM-2010 electron microscope (JEOL, Japan) with a lattice-fringe resolution of $0 \cdot 14 \mathrm{~nm}$ at an accelerating voltage of $200 \mathrm{kV}$. Energy-dispersive X-ray analysis (EDS) was carried out on an EDAX spectrometer (EDAX Co.) fitted with an $\mathrm{Si}$ (Li) detector with a resolution of $130 \mathrm{eV}$. Particles size distributions were calculated using the software «Analysis, v.5» (Soft Imaging System GmbH, 2004). Chemical analysis of the prepared powders was performed by ICP AAS-3 equipment.

\section{Results and discussion}

\subsection{Preparation of nano to submicron sized copper particles}

Figure 1 shows the XRD pattern of the prepared copper powders. Analysis of the XRD pattern shows that there are three phases, the principal one being $\mathrm{Cu}$ (PDF 4-836) $\left(>97 \%\right.$ ), with traces of $\mathrm{Cu}_{2} \mathrm{O}$ (PDF 5-667) and $\mathrm{CuO}$ (PDF 5-661). This partial oxidation of copper is thought to be caused by the presence of a small amount of air in the evaporation chamber. It has been suggested that cuprite is formed not as a surface layer but as separate particles during the preparation of nanosized copper by the pulsed power technique (Sarathi et al 2006). Therefore, the small amount of the cuprite formed in the present experiments may also represent separate oxide particles.

A TEM micrograph and EDS analysis of the precipitated copper particles is shown in figure 2. The TEM micrograph indicates that the copper particles are relatively large and spherical in shape. A wide range of particle sizes was observed. EDS analysis shows that the powders are pure copper without significant impurities. Absence of oxygen in the EDS spectrum supports the $\mathrm{XRD}$ viz. that the majority of the sample is $\mathrm{Cu}$. Particle size analysis suggests that most of the particles are less than $100 \mathrm{~nm}$ in size, with larger particles up to $750 \mathrm{~nm}$ also present (figure 3). The mean particle size of the copper particles lies within the $200 \mathrm{~nm}$ size range, viz. nano to submicron size.

These experiments on the preparation of fine sized copper particles indicate that metallic copper particles with nano to submicron size range can be prepared under the present experimental conditions but have a nonuniform particle size distribution. Therefore, it is important to determine the experimental conditions necessary to obtain a more uniform size distribution.

\subsection{Preparation of silicon/copper composite particles}

The XRD pattern of the silicon/copper composite powder is shown in figure 4 . The XRD pattern shows a relatively higher proportion of copper oxide compared with the pure copper particles, indicating a higher percentage of oxygen in the reaction chamber than in the previous experiment. Since the experimental conditions were similar to those previously used, the additional oxygen may have accompanied the silicon as an oxide layer on the metal surface. The state of the cuprite is not clear at present,

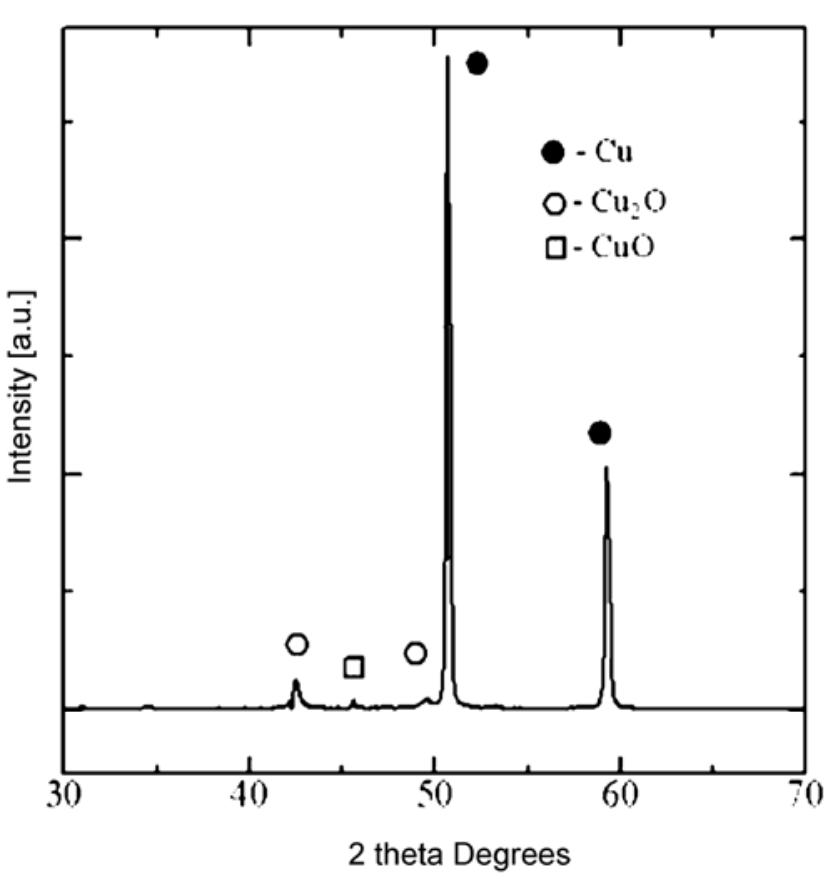

Figure 1. XRD pattern of the copper particles. 

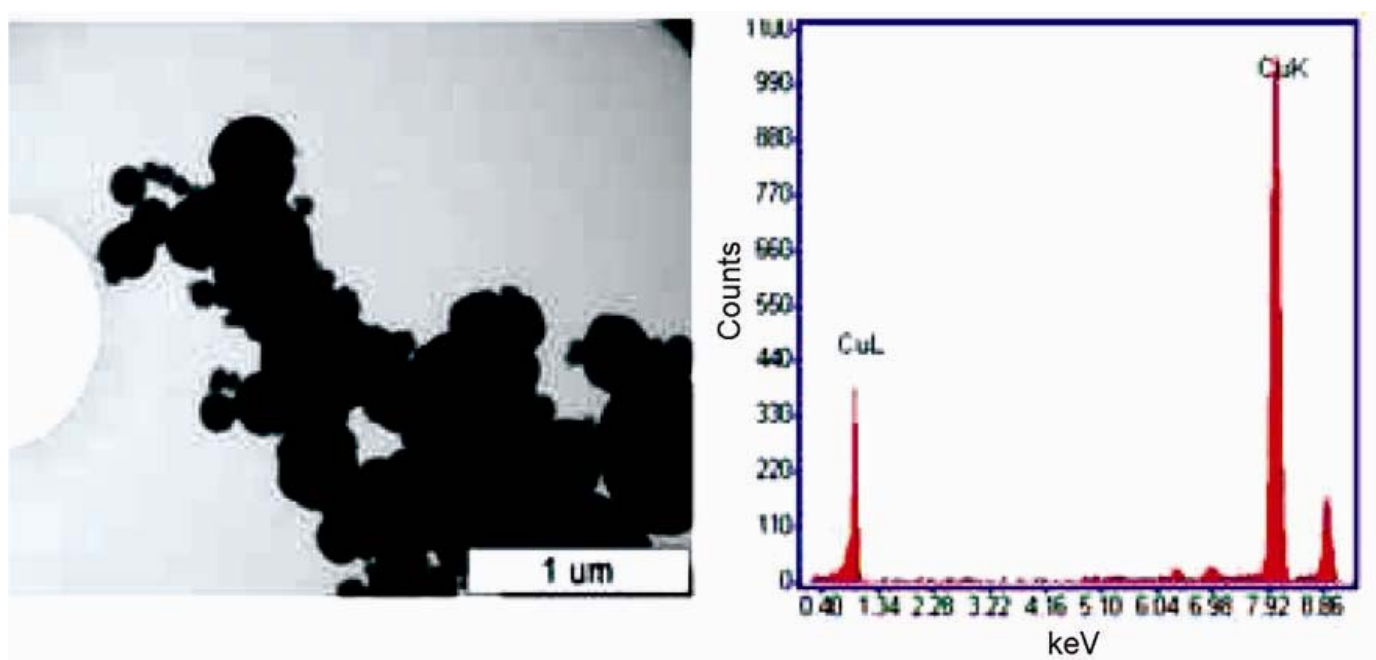

Figure 2. TEM micrograph and EDS of the precipitated copper particles.

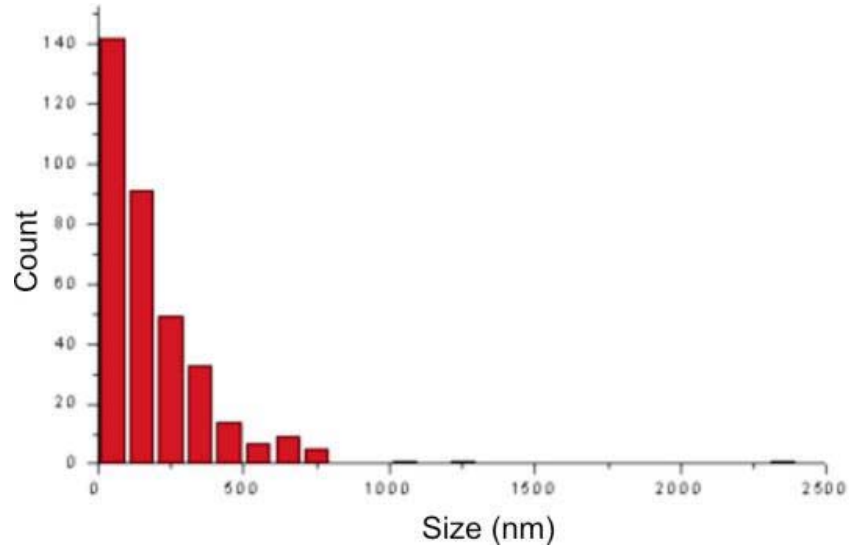

Figure 3. Copper powder particle size distribution.

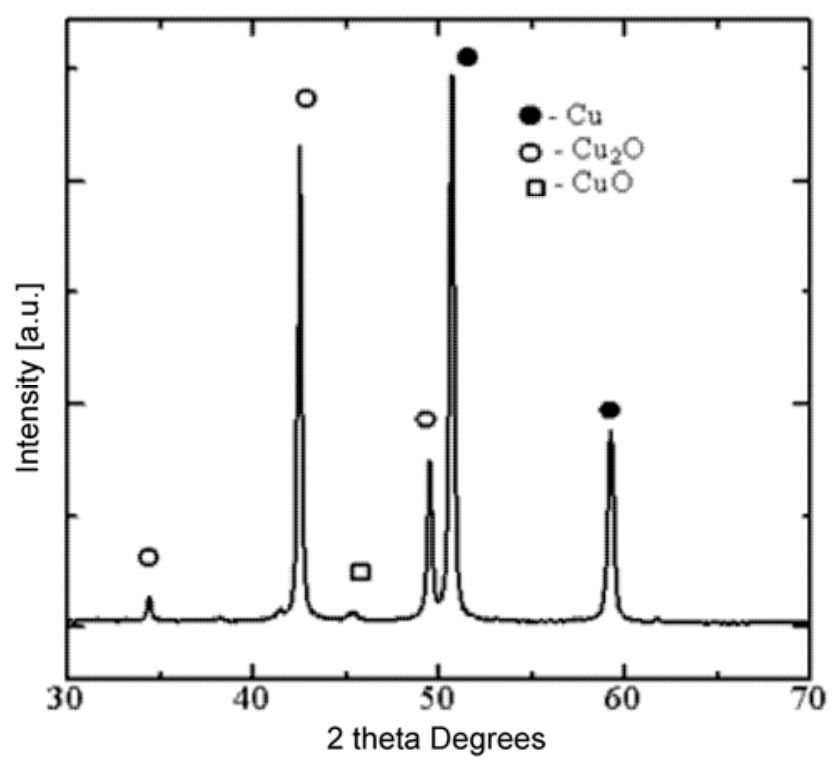

Figure 4. XRD pattern of silicon/copper powder. either it exists as separate particle or as a coating over the copper particles. The copper diffraction lines were broader than in pure copper possibly, indicating a smaller crystallite size or lattice strain of the composite sample (The full width at half-maximum (FWHM) of the XRD (111) peak of the $\mathrm{Cu}$ in the composite sample was $0 \cdot 319^{\circ}$. The FWHM of the same peak in the pure copper sample was $0 \cdot 206^{\circ}$ ). However, there were no peaks that could be assigned to either $\mathrm{Si}$ or $\mathrm{SiO}_{2}$ which indicates that the silicon compounds are in an amorphous state.

Figure 5 shows a TEM micrograph of the composite particles. The TEM micrograph clearly indicates that powders with large range of sizes have been prepared. The sample contains small particles $<100 \mathrm{~nm}$ in size and composite silicon/copper particles, occurring as siliconcoated copper spheres. The uniform Si coating is $\sim 11 \mathrm{~nm}$ thick. It is also possible that some silicon may exist in oxidized condition as amorphous $\mathrm{SiO}_{2}$. The smaller particles with no coating are copper. The size of the composite particles is smaller than the pure copper particles prepared in the previous experiment.

A possible mechanism for composite powder formation is as follows: after evaporation of the copper and silica from the liquid metal surface, the mixed vapour of copper and silicon is carried by the argon gas. Since the evaporation temperature of the silicon $\left(3249^{\circ} \mathrm{C}\right)$ is higher than copper $\left(2567^{\circ} \mathrm{C}\right)$, silicon liquid droplets start to form in the colder zone. However, the high vapour pressure of copper and relatively small amount of silicon does not allow all the silicon from the gas phase to transform to pure silicon droplets instead silicon droplets filled with copper vapour are formed. When these arrive at the colder zone, the composite particles will be spheres of liquid copper coated with solid silicon. As the temperature of the composite decreases the liquid copper will 
solidify in the colder zone. Formation of a solid Si coating over liquid $\mathrm{Cu}$ which then solidifies will result in considerable strain in both materials due to thermal contraction mismatch - this may contribute to the observed line broadening in the XRD pattern.

Research on the preparation of copper nano particles by the pulsed power technique has shown that increasing the pressure reduces size of the particles (Sarathi et al 2006). Since the composite powder preparation chamber contains a high vapour pressure because of the presence of two different metal vapours, the smaller particle size of the composite appears to be consistent with the TEM observation. Surface coating of powders by other compounds is usually achieved by electrostatic attraction suggesting that there should be a charge difference between silicon and copper particles during the droplet

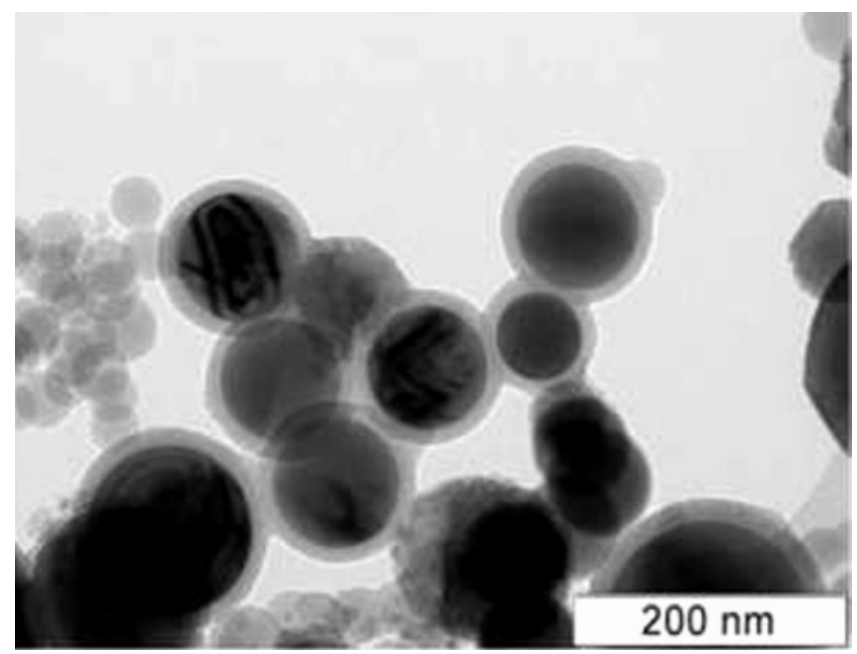

Figure 5. TEM micrograph of the composite silicon/copper particles.

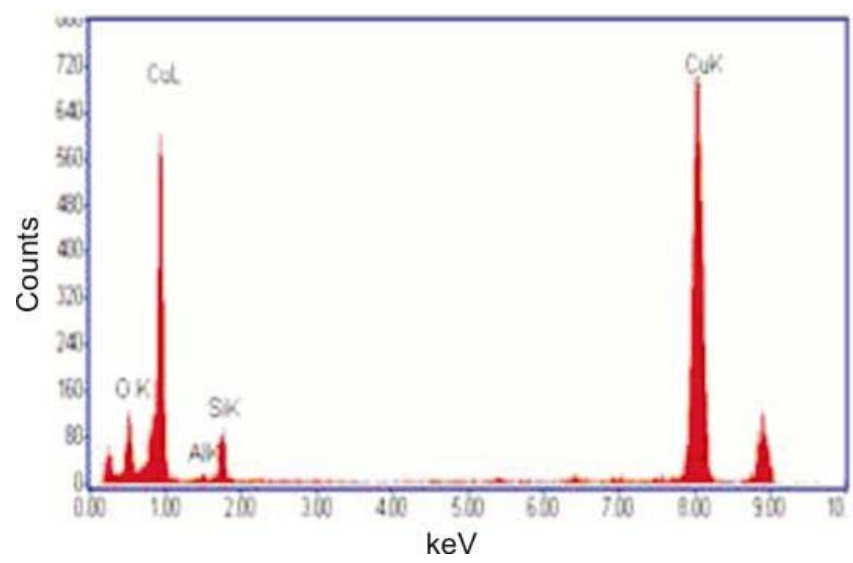

Figure 6. EDS analysis of the silicon/copper composite particles. formation. EDS analyses of the powder is shown in figure 6 .

The nanosilicon copper particles show small amounts of impurities $(\mathrm{Ca}<0.04, \mathrm{Fe}<0.04, \mathrm{Na}<0.03, \mathrm{Ti}<$ $0.02 \mathrm{wt} \%$ ). These impurities probably arose from the starting materials or from the woven filter. The strong intensity of the $\mathrm{CuL}$ line in the EDS spectrum arises from the TEM grid. The nanoparticles contain $6.34 \mathrm{wt} \% \mathrm{Si}$ and 88.9 wt. \% Cu. The particle size distribution of the composite particles is shown in figure 7 .

The particle size distribution shows considerable scatter, with a mean particle size $>100 \mathrm{~nm}$. The particle size of the composite particles is within the same range as other powders such as Mo and Ni prepared by the same equipment (Bardakhanov et al 2006).

The present research indicates that nano to submicronsized copper and silicon/copper composite particles can be prepared by the gas evaporation-condensation method. It may be possible to regulate the size of the composite particles by changing the pressure and velocity of the carrier gas in results of different time of delivery to cold zone. Experiments for tailoring the particle size of the copper powders by changing the pressure and velocity of the carrier gas and understanding of a real mechanism of composite formation are under consideration.

Rapid cooling of the metal vapours creates nonequilibrium solidification which results in extension of solid solubility, solute trapping, disorder trapping, amorphization in the evolution of novel metastable phases and microstructure in the solidified surface layer (Bysakh et al 2004), which may show an influence on the properties of prepared powders. Therefore, it is important to determine the real mechanism of the composite particle formation. In contrast to previous research on preparation of fine sized (nano to submicron) copper particles the present method allows production of copper and silicon/ copper composite particles with yields of several hundred grams per hour.

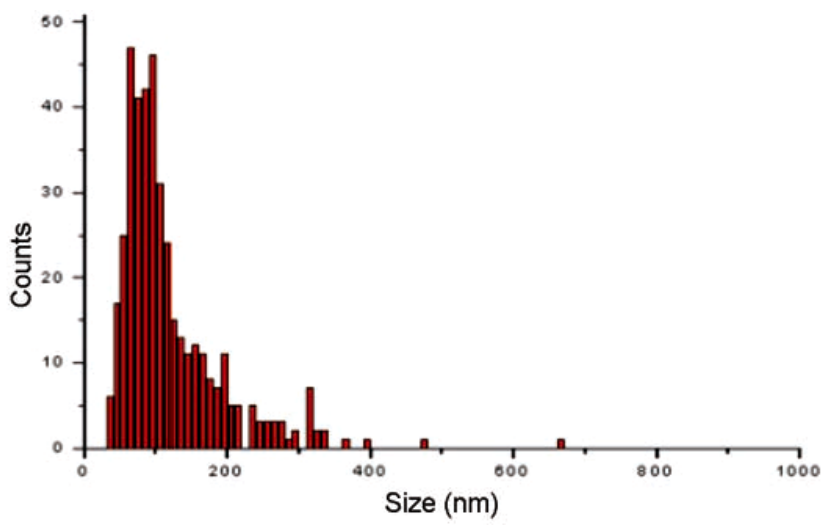

Figure 7. Particle size distribution of the composite particles. 


\section{Conclusions}

Nano to submicron-sized copper and composite silicon/ copper particles can be prepared by a gas evaporationcondensation method. The pure copper particles are spherical in shape with a median size of about $200 \mathrm{~nm}$, while the composite particles consist of two different types, the larger composites having a size range of 70 $200 \mathrm{~nm}$ and the smaller being nanopowders with a size range of $40-70 \mathrm{~nm}$.

\section{Acknowledgements}

The present research was supported by the integration project 'Study of properties of nano powders of metals, oxides, nitrides synthesized after condensation of high temperature vapor' No. 07-02-90103-Mong_a of the Russian Fund for Basic Research and Mongolian Minister of the Science, Education and Culture. The authors also wish to thank Dr K J D MacKenzie, Victoria University, Wellington, for his fruitful comments.

\section{References}

Bardakhanov S P, Korchagin A I, Kuksanov N K, Lavrukhin A V, Salimov R A, Fadeev S N and Cherepkov V V 2006 Mater. Sci. \& Eng. B132 204

Bysakh S, Chattopadhyay K, Maiwald T, Galun R and Mordike B L 2004 Mater. Sci. \& Eng. A375-377 661

Ilyin A P 2007 Private communication

Hsu W P, Yu R and Matijevic E 1990 Powder Technol. 63265

Gleiter H 2000 Acta Mater. 481

Kim N S, Amert A K, Woessner S M, Decker S, Kang S M and Han K N 2007 J. Nanosci. \& Nanotechnol. 73902

Korchagin A I et al 2005 Vacuum 77458

Liu Y, Chu Y, Zhuo Y, Dong L, Li L and Li M $2007 A d v$. Function. Mater. 17933

Ramsey J D F and Avery R G 1974 J. Mater. Sci. 91681

Sarathi R, Murai K, Kobayashi R, Suematsu H, Jiang W and Yatsui K 2006 Synth. React. Inorg., Metal-Organ. \& NanoMetal Chem. 36127

Srikanth N, Thein M and Gupta M 2004 Mater. Sci. \& Eng. A366 38

Terekhov V A et al 2008 Mater. Sci. \& Eng. B147 222

Wu N Q, Su L Z, Yuan M Y, Liu Y Y, Wu J M and Li Z Z 1998 Trans. Nonferr. Metals Soc. China 8610 